\title{
DIAGNÓSTICO DE SINTOMAS DE DEFICIÊNCIA DE MACRONUTRIENTES EM PIMENTEIRA DO REINO (Piper nigrum, L.)
}

\author{
C.A.C. VELOSO \\ Centro de Pesquisa Agroflorestal da Amazonia Oriental, EMBRAPA, C.P. 48, CEP: 66.095-100-Belém, PA. \\ T. MURAOKA \\ Centro de Energla Nuclear na Agricultura/USP, C.P. 96, CEP: 13400-970 - Piracicaba, SP.
}

\begin{abstract}
RaSUMO: Com o propósito de caracterizar os sintomas de deficiências dos macronutrientes em pimenteira do reino (Piper nigrum L.), conduxiu-se um ensaio usando mudas de pimenteira, cultivar "Guajarina", cultivadas em vasos contendo splica, com as seguintes soluções nutritivas: omissão de $\mathbf{N}$, omissão de $P$, omissão de $K$, omissão de $C a$, omissão de Mg, omissão de S, e solução nutritiva completa. Após um período compreendido entre 90-150 dias, começaram a aparecer os sintomas de deficiência devido a omissão dos macronutrientes. Os nutrientes mais absorvidos foram potássio e o nitrogênio, seguindo-se pela ordem decrescente o cálcio, o magnésio, o enxofre e o fósforo. Concluiu-se que a omissăo de nitrogenio foi o tratamento que mais afetou o desenvolvimento das plantas. Pela ordem decrescente, seguiram-se os das ausências de cálcio e de potássio. Os indices analíticos em folhas do tratamento completo e na omissão foram: $N=1,89$ e $1,39 \%, P=0,12$ e $0,06 \%, K=2,19$ e $1,22 \%, C a=1,04$ e $0,73 \%, \mathrm{Mg}=0,35$ e $0,14 \%, S=0,18$ e $0,12 \%$.

Deacritore: pimenta do reino, nutrição, sintomas de deficiência, diagnose visual.
\end{abstract}

\section{DIAGNOSIS OF MACRONUTRIENT DEFICIENCY SYMPTOMS IN BLACK PEPPER (Piper nigrum, L.)}

\begin{abstract}
To characterize macronutrient deficiencies in black pepper plants (Piper nigrum L.), an experiment was conducted using pepper cuttings, "Guajarina" cultivar, grown in pots containing silex and the following nutrient solutions: $-\mathrm{N},-\mathrm{P},-\mathrm{K},-\mathrm{Ca},-\mathrm{Mg},-\mathrm{S}$ and complete. The nutrient deficiencies were described at 90 and 150 days after omission of nutrients. The most absorbed nutrients were potassium and nitrogen, followed by $\mathrm{Ca}, \mathrm{Mg}, \mathrm{S}$ and $\mathrm{P}$. The omission of $\mathrm{N}$ was the treatment which most afected plant growth, followed by $\mathrm{Ca}$ and $\mathrm{K}$. The analytical indices in the leaves of complete and omission treatments were respectively: $N=1.89$ and $1.39 \%, P=0.12$ and $0.06 \%, K=$ 2.19 and $1.22 \%, \mathrm{Ca}=1.04$ and $0.73 \%, \mathrm{Mg}=0.35$ and $0.14 \%, \mathrm{~S}=0.18$ and $0.12 \%$.
\end{abstract}

Key Words: black pepper, nutrition deficiency, symptoms, visual diagnosis.

\section{INTRODUÇÃO}

O conhecimento da nutrição da pimenteira do reino é bastante incipiente, não tendo sido, ainda, determinados os disturbios ocasionados pelas deficiências ou excessos de nutrientes.

Entretanto, como as desordens nutricionais: deficiências, excessos e desequilibrios, causam diminuição na produção de qualquer cultura, a pimenteira não constitui exceção.

Essa diminuição na colheita é, em geral, precedida por sintomas visuais, que geralmente são mais evidentes nas folhas, embora a produção possa já estar comprometida, mesmo antes da manifestação dos mesmos (MALAVOLTA et al., 1989).
A diagnose visual de deficiências nutricionais em folhas de pimenteiras bem como o conhecimento dos teores de nutrientes, podem constituir uma técnica auxiliar nos cálculos de fertilizantes e corretivos (MALAVOLTA, 1980).

Por outro lado, a técnica do cultivo de plantas em substrato que não seja o solo, tem permitido avanços no conhecimento da nutrição das plantas, pois controla mais adequadamente a composição da solução e elimina a heterogeneidade e complexidade que se apresenta no solo (EPSTEIN, 1975). Com o intuito de obter um melhor conhecimento das necessidades nutricionais da cultura, o presente trabalho teve como objetivo, caracterizar os sintomas de deficiências de nitrogênio, fósforo, potássio, cálcio, magnésio e enxofre. 


\section{MATERIAL E MÉTODOS}

O experimento foi conduzido em casa de vegetação do Centro de Pesquisa Agroflorestal da Amazonia Oriental (EMBRAPA-CPATU). As mudas foram obtidas de estacas herbáceas com dois entre-nós e uma folha, do cultivar Guajarina. Quando as mudas atingiram a idade de $\mathbf{9 0}$ dias foram transplantadas para vasos de plástico com capacidadede para $4 \mathrm{~kg}$ de sílica. As plântulas foram irrigadas com solução nutritiva completa segundo (WAARD, 1969) diluída na proporção $1: 1$, onde permaneceram por quatro semanas. $A$ solução foi renovada a cada duas semanas. Após êste período iniciou-se os tratamentos, irrigando-se 2 vezes ao dia com as soluções nutritiva de WAARD (1969), nas quais se omitia um nutriente de cada vez conforme a Figura 1. Os tratamentos utilizados foram: omissão de nitrogênio, omissão de fósforo, omissão de potássio, omissão de cálcio, omissão de magnésio, omissão de enxofre e solução nutritiva completa. Usou-se $o$ delineamento experimental inteiramente casualizado com três repetições. Diariamente, o volume destas soluções era verificado, completando-se a 1 litro pela adição de água deionizada. As soluções foram renovadas a cada 15 dias.

Após 90-150 dias, quando começaram a se manifestar os sintomas de deficiência, devidos a omissão dos macronutrientes, procedeu-se a coleta das plantas, separando-as em folhas e em caules. O material colhido foi acondicionado em saco de papel e colocado em estufa com circulação forçada de ar, à 60 a $70^{\circ} \mathrm{C}$, até atingir peso constante. Após a determinação do peso da matéria seca, procedeu-se à moagem do material em moinho Willey com peneira de 20 mesh, para determinação química de $\mathrm{N}, \mathrm{P}, \mathrm{K}, \mathrm{Ca}, \mathrm{Mg}$ e $\mathrm{S}$, segundo metodologia descrita por SARRUGE \& HAAG (1974).

\section{RESULTADOS E DISCUSSÀO}

\section{Deficiência de nitrogenio}

Noventa dias após a omissão desse nutriente, as plantas mostraram os primeiros sintomas, caracterizados por leve amarelecimento generalizado nas folhas, sendo mais evidente nas mais velhas, que iniciou com verde amarelado, distribuindo-se uniformemente no limbo, no peciolo e nas nervuras. Trinta dias após o início dos sintomas verificou-se menor desenvolvimento das plantas em relação ao tratamento completo, e a partir desse período o amarelecimento tornou-se mais acentuado. Os sintomas descritos concordam parcialmente com WAARD (1969).

\section{Deficiência de fósforo}

Cento e cinquenta dias após a omissão desse nutriente, observava-se as plantas com caules finos e um recurvamento para cima das folhas mais jovens e posteriormente as mais velhas, sendo que estas folhas eram pequenas e estreitas. Com relação a cor, as folhas mostraram coloração verde azulado com tons purpureo na face superior do limbo e ásperas ao tato. $O$ crescimento das pimenteiras foi reduzido comparado com o tratamento completo. Em outros trabalhos são citados sintomas semelhantes (ALBUQUERQUE \& CONDURU, 1971 e MILANEZ 1984).

\section{Deficiência de potássio}

Cento e trinta e cinco dias após a omissão desse nutriente, apareceram os sintomas de deficiência de potássio caracterizados por um princípio de necrose nas margens e pontas de folhas mais velhas e logo a seguir, nas folhas jovens, sendo de consistência quebradiça. Vinte dias após o início dos sintomas, houve um escurecimento de áreas situadas entre as nervuras, com posterior necrose, confirmando os sintomas descritos por WAARD (1969).

\section{Deficiência de cálcio}

Aos cento e trinta e cinco dias após o início do tratamento, ocorreram os primeiros sintomas de deficiência de cálcio, caracterizados por um leve amarelecimento das folhas mais jovens, com pequenas manchas pardas necróticas na face superior das folhas mais velhas. Com o avanço da deficiência, surgiram manchas necróticas nas bordas das folhas. A parte basal da folha, ocorreu uma coloração amarelo pálida com pequenas manchas necróticas, semelhante a pequenas pontuações. Os sintomas descritos concordam em parte com WAARD (1969).

\section{Deficiência de magnésio}

Os sintomas de deficiência de magnésio iniciaram-se cento e vinte e cinco dias desde o início do tratamento. Inicialmente, as folhas mais 


\begin{tabular}{|c|c|c|c|c|c|c|c|}
\hline \multirow{2}{*}{$\begin{array}{l}\text { Soluções } \\
\text { Estoque }\end{array}$} & \multirow[b]{2}{*}{ Completo } & \multirow[b]{2}{*}{$-\mathrm{N}$} & \multirow[b]{2}{*}{$\mathbf{- P}$} & \multicolumn{2}{|c|}{ Tratamentos } & \multirow[b]{2}{*}{$-\mathbf{M g}$} & \multirow[b]{2}{*}{$-S$} \\
\hline & & & & $-K$ & $-\mathrm{Ca}$ & & \\
\hline $\mathrm{NH}_{4} \mathrm{NO}_{3} \quad \mathrm{M}$ & 3 & - & 3 & 3 & 3 & 3 & 3 \\
\hline $\mathrm{Ca}\left(\mathrm{NO}_{3}\right)_{2} \mathrm{M}$ & 4 & - & 4 & 4 & - & 4 & - \\
\hline $\mathrm{NaH}_{2} \mathrm{PO}_{4} \mathrm{M}$ & 1 & 1 & - & 1 & 1 & 1 & 1 \\
\hline $\mathrm{Na}_{2} \mathrm{SO}_{4} \quad \mathrm{M}$ & - & - & - & - & - & 2 & - \\
\hline $\mathrm{MgSO}_{4} \quad \mathrm{M}$ & 2 & 2 & 2 & 2 & 2 & - & - \\
\hline $\mathrm{KNO}_{3} \quad \mathrm{M}$ & 2 & - & 2 & - & 2 & 2 & 2 \\
\hline $\mathrm{CaCl}_{2} \quad \mathrm{M}$ & - & 4 & - & - & - & - & 4 \\
\hline $\mathrm{NaNO}_{3} \quad \mathrm{M}$ & - & - & - & 2 & 8 & - & 4 \\
\hline $\mathrm{Mg}\left(\mathrm{NO}_{3}\right)_{2} \mathrm{M}$ & - & - & - & - & - & - & 2 \\
\hline $\mathrm{KCl}$ & - & 2 & - & - & - & - & - \\
\hline Micro* & 1 & 1 & 1 & 1 & 1 & 1 & 1 \\
\hline Fe-EDTA & 4 & 4 & 4 & 4 & 4 & 4 & 4 \\
\hline
\end{tabular}

Figura 1 - Composição química das soluções nutritivas (ml/l), segundo WAARD (1969) modificada.

velhas apresentaram amarelecimento e clorose internerval, com uma faixa estreita de tecido verde permanecendo ao longo das nervuras. A seguir, partes das margens das folhas apareceram necrosadas. Os primeiros sintomas foram detectados nas folhas mais velhas. No fim do cultivo, algumas folhas jovens mostravam pequeno amarelecimento e clorose internerval, concordando com os sintomas relatados por WAARD (1969); MORAES (1968) e SIM (1974).

\section{Deficiencia de enxofre}

Os sintomas de deficiência de enxofre iniciaram-se cento e quarenta dias após a omissão desse nutriente; observou-se que, as folhas novas das pimenteiras deficientes em enxofre apresentaram-se pequenas, com coloração verde mais claro, em relação às folhas de pimenteiras do tratamento completo.

\section{Produção de matéria seca}

Os dados relativos ao peso da matéria seca produzida pelos tratamentos encontram-se na TABELA 1. Verifica-se que, os tratamentos que mais a fetaram o crescimento da pimenteira do reino foram a omissão de nitrogênio, cálcio e potássio.

A omissão de enxofre, fósforo e de magnésio não afetaram o crescimento.

As concentrações médias de macronutrientes nas folhas e nos caule da pimenteira do reino "Guajarina", cultivadas em soluções nutritivas, completa e deficientes, encontram-se na TABELA 2.

Observa-se, que ocorreu maior teor e acúmulo dos nutrientes nas folhas e caule do tratamento completo em relação aos tratamentos com omissão dos nutrientes.

Em relação à acumulação de nutrientes, a maior absorção ocorreu na ausência de potássio, enquanto a menor absorção ocorreu na ausência fósforo.

A absorção de nutrientes pela pimenteira, ocorreu da seguinte maneira: $\mathrm{K}>\mathrm{N}$ $>\mathrm{Ca}>\mathrm{Mg}>\mathrm{S}>\mathrm{P}$.

Tais observações concordam com aquelas relatadas por SIM (1971). 
TABELA 1 - Produções médias de matéria seca de folhas, caule e total de plantas de pimenta do reino em função dos tratamentos (média de três repetiçôes).

\begin{tabular}{lccc}
\hline \hline & & Parte aérea da planta \\
Tratamento & Folhas & Caule & Total \\
\hline & & g/planta \\
Completo & $20,2 \mathrm{a}$ & $18,7 \mathrm{ab}$ & $38,9 \mathrm{a}$ \\
Omissão de N & $8,1 \mathrm{a}$ & $7,5 \mathrm{~d}$ & $15,6 \mathrm{c}$ \\
Omissão de P & $19,3 \mathrm{a}$ & $17,0 \mathrm{abc}$ & $36,3 \mathrm{a}$ \\
Omissão de K & $14,4 \mathrm{~b}$ & $14,7 \mathrm{bc}$ & $29,1 \mathrm{~b}$ \\
Omissão de Ca & $14,4 \mathrm{~b}$ & $13,5 \mathrm{c}$ & $27,9 \mathrm{~b}$ \\
Omissão de Mg & $20,4 \mathrm{a}$ & $19,5 \mathrm{a}$ & $39,9 \mathrm{a}$ \\
Omissão de S & $21,2 \mathrm{a}$ & 17,7 abc & $38,9 \mathrm{a}$ \\
\hline DMS Tukey (5\%) & 4,18 & 4,66 & 6,20 \\
C.V. (\%) & 8,89 & 10,76 & 6,87 \\
\hline \hline
\end{tabular}

Médias seguidas da mesma letra não diferem entre si pelo teste de Tukey ao nível de $5 \%$ de probabilidade.

TABELA 2 - Teor (\%) e acúmulo (mg/planta) de macronutrientes nas folhas e caule de pimenteiras do reino em função dos tratamentos.

\begin{tabular}{lcccc}
\hline & \multicolumn{4}{c}{ Parte aérea da planta } \\
\cline { 2 - 5 } Tratamento & \multicolumn{3}{c}{ Folhas } & Caule \\
\cline { 2 - 5 } & 1,89 & 381,78 & 1,29 & $\mathrm{mg}$ \\
\hline Completo & 1,39 & 112,59 & 0,95 & 241,23 \\
Omissão de N & 0,12 & 24,24 & 0,13 & 71,25 \\
Completo & 0,06 & 11,58 & 0,06 & 24,31 \\
Omissão de P & 2,19 & 442,38 & 2,09 & 10,20 \\
Completo & 1,22 & 175,68 & 1,17 & 390,83 \\
Omissão de K & 1,04 & 210,08 & 0,55 & 171,99 \\
Completo & 0,73 & 105,12 & 0,17 & 102,85 \\
Omissão de Ca & 0,35 & 70,70 & 0,13 & 22,95 \\
Completo & 0,14 & 28,56 & 0,04 & 24,31 \\
Omissão de Mg & 0,18 & 36,36 & 0,16 & 7,80 \\
Completo & 0,12 & 15,44 & 0,10 & 29,92 \\
Omissão de S & & & & 17,70 \\
\hline \hline
\end{tabular}




\section{CONCLUSÕES}

Os nutrientes absorvidos em maiores quantidades foram o $\mathrm{K}$ e o $\mathrm{N}$, seguindo-se em ordem decrescente $\mathrm{Ca}>\mathbf{M g}>\mathrm{S}>\mathrm{P}$. A omissão de nitrogênio foi o tratamento que mais afetou $O$ desenvolvimento das pimenteiras do reino, seguindo-se os de ausência de cálcio e de potássio. Os teores dos nutrientes nas folhas do tratamento completo e na omissão foram: $N=1,89$ e $1,39 \%$, $\mathrm{P}=0,12$ e $0,06 \%, \mathrm{~K}=2,19$ e $1,22 \%, \mathrm{Ca}=1,04$ e $0,73 \%, \mathrm{Mg}=0,35$ e $0,14 \%, \mathrm{~S}=0,18$ e $0,12 \%$.

\section{REFERÊNCIAS BIBLIOGRÁFICAS}

ALBUQUERQUE, F.C. de; CONDURU, J.M.P. Cultura da pimenta do reino na regiâo amazónica. Série Fitotecnia, Belém, v.2. n.3, p.1-149, 1971.

EPSTEIN, E. Nutriçâo mineral de plantas: principios e perspectivas. Rio de Janeiro: Livros Técnicos e Científicos, 1975. 341p.

MALAVOLTA, E. Elementos de nutrição mineral de plantas. São Paulo, Editora Agronômica Ceres, 1980. 251 p.

MALAVOLTA, E.; VITTI, G.C.; OLIVEIRA, S.A. de. Avaliação do estado nutricional das plantas: princípios e aplicações. Piracicaba: Associação Brasileira para Pesquisa da Potassa e do Fosfato, 1989. 201p.
MILANEZ, D. Levantamento nutricional de pimenteiras do reino no Espirito Santo pela análise foliar. Cariacica: EMCAPA, 1984. 23p. (EMCAPA. Boletim de Pesquisa, 5).

MORAES, V.H.F. Ocorrência de deficiência de magnésio em pimenta do reino (Piper nigrum, L.) em condições de campo. Pesquisa Agropecuária Brasileira, Rio de Janeiro, v.3, p.147-149, 1968.

SARRUGE, J.R.; HAAG, H.P. Análises químicas em plantas. Piracicaba, ESALQ, 1974. 56p.

SIM, E.S. Dry matter production and major nutrient contents of black pepper (Piper nigrim, L.) in Sarawak. Malaysian Agricultural Journal, Kuala Lumpur, v.48, n.2, p.73-93, 1971 .

SIM, E.S. A nutrient survey of black pepper small holdings in Sarawak. Malaysian Agricultural Journal, Kuala Lumpur, v.49, n.3, p.365-380, 1974.

WAARD, P.W.F. de. Foliar diagnosis nutrition and yield stability of black pepper (Piper nigrum, L.) in Sarawak. Amsterdam: Tropical Institute, 1969. 149p. (Communication, 58).

Trabalho enviado para publicação em 12.06 .92

Trabalho aceito para publicação em 15.02.93 